Alan Appelbaum

\title{
The Dynasty of the Jewish Patriarchs
}

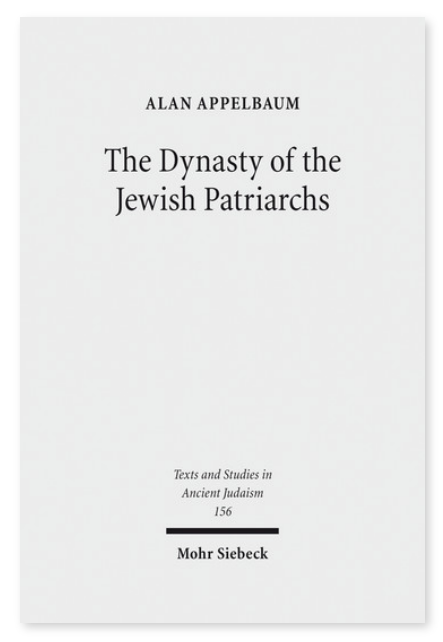

2013. XI, 246 Seiten. TSAJ 156

ISBN 978-3-16-152969-6

DOI 10.1628/978-3-16-152969-6

eBook PDF $114,00 €$

ISBN 978-3-16-152964-1

Leinen $114,00 €$
[Die Dynastie der jüdischen Patriarchen.]

Veröffentlicht auf Englisch.

Die jüdischen Patriarchen waren bemerkenswert, nicht nur, weil sie einen großen Teil Palästinas in der Spätantike regierten, Steuern von Juden einzogen und ihnen Abgesandte durch das römische Reich schickten, als Repräsentanten sowohl der palästinensischen als auch der Diaspora-Juden gegenüber der Regierung des römischen Imperiums dienten und zu großer Prominenz in der römischen Gesellschaft gelangten. Sie waren auch bemerkenswert, weil sie die Juden für mehr als zwei Jahrhunderte anführten und das Patriarchat dabei dennoch immer Sache der Familie blieb. Alan Appelbaum untersucht das Patriarchat erstmalig als vererbbare Dynastie, als eine Reihe von Männern in speziellen sozialen Strukturen statt als einer Institution. Er zieht dabei jüdische, christliche und heidnische Quellen in Betracht, einschließlich der römischen Gesetze, welche noch nie in diesem Rahmen berücksichtigt wurden. Zudem vergleicht er das Patriarchat mit anderen echten und vermeintlichen Dynastien, um es innerhalb der verschiedenen familiären Konstellationen dieser Zeit einzuordnen.

Alan Appelbaum Born 1936; 2007 PhD Yale University; research affiliate, Department of Religious Studies, Yale University; senior counsel, Cleary Gottlieb Steen \& Hamilton LLP; currently visiting fellow in the Judaic Studies Program, Yale University.
Jetzt bestellen:

https://mohrsiebeck.com/buch/the-dynasty-of-the-jewish-patriarchs-9783161529696?no_cache=1

order@mohrsiebeck.com

Telefon: +49 (0)7071-923-17

Telefax: +49 (0)7071-51104 